\title{
Efektivitas Hemodialisa Berdasarkan Parameter Hemoglobin, Eritrosit, Dan Hematokrit Pada Penderita Gagal Ginjal Kronik
}

\author{
Desy Dwi Rosini ${ }^{1}$ Aini $^{2}$, Eri Ramadanti ${ }^{3}$ \\ 123 Program Studi DIII Teknologi Laboratorium Medik, Politeknik Medica Farma Husada \\ Mataram
}

Article Info

Article history:

Received, Jul $14^{\text {th }}, 2020$

Revised, Sep $19^{\text {th }}, 2020$

Accepted, Sep $20^{\text {th }}, 2020$

\section{Keyword:}

Hemodialysis, Kidney failure, Hemoglobin, Erythrocytes

\begin{abstract}
Various diseases that cause kidney dysfunction that cause problems in the body such as the accumulation of metabolic waste, decreased hormone production that can cause chronic kidney failure. Hemodialysis is used to replace damaged kidney function, in patients with kidney failure who undergo hemodialysis will experience anemia (80-95\%). This study aims to determine the effectiveness of hemodialysis in patients with chronic renal failure. This study uses an observational analytic method using primary data with a total sample of 30 respondents. This research was conducted in May at the AsySyifa Regional Hospital in West Sumbawa. Statistic test uses Wilcoxon because it is found that the data is not normally distributed, that is $<0.05$. The results of this study indicate that there is an increase in hemoglobin levels, hematocrit values, and the number of erythrocytes after hemodialysis.
\end{abstract}

Copyright (O Jurnal Analis Medika Biosains (JAMBS) All rights reserved.

\begin{abstract}
ABSTRAK
Berbagai penyakit yang menyebaabkan gangguan fungsi ginjal sehingga menimbulkan masalah pada tubuh seperti penumpukan sisa metabolisme, penurunan produksi hormon yang dapat menyebabkan gagl ginjal kronik. Hemodialisa digunakan untuk memggantikan fungsi ginjalyang rusak, pada penderita gagal ginjal yang menjalani hemodialisa akan mengalami anemia (80-95\%). Penelitian ini bertujuan untuk mengetahui efektifitas hemodialisa pada pasien gagal ginjal kronik. Penelitian ini menggunakan metode observasional analitik dengan menggunakan data primerdengan jumlah sampel sebanyak 30 responden. Penelitian ini dilaksanakan pada bulan mei di RSUD Asy-Syifa Sumbawa Barat. Uji statistic menggunakan Wilcoxon karena didapatkan data tidak berdistribusi normal yaitu <0,05. Hasil penelitian ini menunjukkan bahwa ada peningkatan kadar hemoglobin, nilai hematokrit, dan jumlah eritrosit sesudah hemodialisa.
\end{abstract}

Kata kunci: Hemodialisa, Gagal Ginjal, Hemoglobin, Eritrosit

\section{Pendahuluan}

Ginjal merupakan salah satu organ vital dalam tubuh yang berperan sangat penting dalam menjaga kesehatan tubuh. Jika ginjal tidak dapat berfungsi sebagaimana mestinya dapat menimbulkan beberapa penyakit seperti penumpukan sisa-sisa metabolisme, dan penurunan produksi hormon yang dapat menyebabkan gagal ginjal kronik("Predictors of survival among end stage renal failure patients undergoing dialysis treatment in Pahang from 2000 to 2004," 2009).

Prevalensinya Penyakit gagal ginjal kronik (GGK) semakin meningkat di Indonesia yang diperkirakan ada sekitar 40-60 kasus pertahun. Data Riskesdas 2018 (RI, 2018) menunjukkan bahwa prevalensi gagal ginjal kronik mencapai $6,4 \%$. Penderita gagal ginjal kronik harus melakukan terapi hemodialisa untuk memperpanjang usia harapan hidup (Suzanne C. Smeltzer, 2013). 
Hemodialisa digunakan sebagai salah satu terapi untuk menggantikan fungsi ginjal yang memburuk akan tetapi penderita yang menjalani hemodialisa selalu mengalami anemia (80-95\%) bahkan ada yang mencapai $100 \%$ dari 86 sampel (Ulya, 2007). Tujuan dilaksanakannya terapi hemodialisa adalah untuk membuang zat sisa metabolisme darah dengan yang tidak diperlukan lagi (Khanmohamadi, 2014). Zat sisa metabolisme ini berupa ureum dan kreatinin yang salah satunya disebabkan oleh gagal ginjal kronik (Adhiatma, Wahab, Fajar, \& Widyantara, 2014).

Kelebihan ureum dan kreatinin di dalam tubuh karena menurunnya fungsi ginjal, tingginya kadar kreatinin dan ureum dapat mengganggu fungsi eritropoitin (Pendidikan, Spesialis, Klinik, Sakit, \& Sadikin, 2016). Eritropoitin adalah hormon yang terutama diproduksi oleh ginjal untuk meningkatkan produksi eritrosit. Hormon Eritropoetin (EPO) $90 \%$ diproduksi oleh ginjal dan 10\% di diproduksi oleh di hati(Utami \& Fuad, 2018) Hormon ini berfungsi untuk merangsang sumsum tulang untuk membentuk sel darah merah. Karena terganggunya fungsi ginjal, akan ginjal tidak dapat memproduksi cukup sehingga terjadi penurunan eritrosit eritropoetin dapat mempengaruhi sumsum tulang untuk membentuk sel darah. Terganggunya fungsi ginjal, makan menyebabkan ginjal tidak dapat memproduksi eritroprotein yang dapat menyebabkan penurunan kadar eritrosit dan nilai hematokrit (Oliver, 2019). Faktor lain yang dapat menyebabkan anemia pada gagal ginjal kronik adalah kehilangan darah pada proses hemodialisa defisiensi besi, defisiensi vitamin, dan akibat perdarahan (Kandarini, 2017).

Pasien gagal ginjal biasanya melakukan hemodialisa dua kali dalam seminggu. Menurut penelitian (Analis, Delima, \& Gresik, 2015) bahwa pasien yang rutin melakukan hemodialisa akan mempengaruhi kadar hemoglobin, jumlah eritrosit dan nilai hematokrit. Perubahan kadar hemoglobin, jumlah eritrosit dan nilai hematokrit pada pasien dengan hemodialisa terkadang sering meningkat bahkan tidak berubah (Widyastuti, Butar-butar, \& Bebasari, 2014). Novelity pada penelitian ini adalah menganalisa efektivitas hemodialisa terhadap beberapa parameter yaitu hemoglobin, eritrosit dan nilai hematokrit sehingga dapat melihat secara keseluruhan efektivitas dari parameter tersebut sedangkan pada jurnal lain hanya melihat perbandingan kadar hemoglobin.

Pasien gagal ginjal kronik di RSUD Asy-syifa yang melakukan hemodialisa sebanyak 7 orang perhari dan penelitian untuk mengetahui efektivitas hemodialisa terhadap paramater tersebut belum dilakukan. Penelitian ini dilakukan untuk mengetahui seberapa efektivitas hemodialisa terhadap kadar hemoglobin, jumlah eritrosit dan nilai hematokrit. Berdasarkan latar belakang di atas, penulis ingin melakukan penelitian tentang efektvitas hemodialisa terhadap pasien gagal ginjal di RSUD Asy-syifa Sumbawa Barat.

\section{Metode Penelitian}

Jenis penelitian adalah penelitian observasional analitik dengan pendekatan cross sectional (Notoatmodjo, n.d.). Tujuanya untuk mengetahui adanya perubahan jumlah kadar hemoglobin, nilai hematokrit dan jumlah eritrosit pada pasien gagal ginjal kronik sebelum dan sesudah hemodialisa. Penelitian ini dilakukan di Rumah Sakit Umum Daerah (RSUD) Asy-Syifa Sumbawa Barat, pada bulan Mei 2019. Besar sampel yang digunakan adalah sampel jenuh penderita yang melakukan hemodialisa selama bulan Mei 2019 yang memenuhi kriteria inklusi dan eksklusi sebanyak 30 sampel. 
Sampel yang digunakan adalah pasien penyakit gagal ginjal kronik yang menjalani hemodialisa di RSUD Asy-Syifa. Variable bebas dalam penelitian ini adalah pasien gagal ginjal kronik yang menjalani hemodialisa, sedangkan variable terikat adalah kadar hemoglobin, nilai hematokrit dan jumlah eritrosit. Instrumen yang digunakan adalah alat hematologi analyzer, Spuit, tabung vakum, alcohol swab Penelitian menggunakan data primer dan diolah menggunakan SPSS uji wilcoxon.

\section{Hasil Penelitian dan Pembahasan}

Data hasil pengukuran terhadap 30 orang responden dengan parameter kadar hemoglobin, nilai hematokrit dan jumlah eritrosit dilakukan sebelum dan sesudah hemodialisa

\begin{tabular}{|c|c|c|c|c|c|c|c|c|}
\hline \multirow[t]{2}{*}{ No } & \multirow{2}{*}{$\underset{\mathrm{a}}{\mathrm{Nam}}$} & \multirow{2}{*}{$\begin{array}{l}\text { Jenis } \\
\text { Kelamin }\end{array}$} & \multicolumn{3}{|c|}{ Sebelum } & \multicolumn{3}{|c|}{ Sesudah } \\
\hline & & & $\mathbf{H b}$ & Ht & Eri & Hb & Hit & Erí \\
\hline 1 & Al & L & 10.5 & 33.7 & 3.4 & 11 & 34.7 & 3.6 \\
\hline 2 & $\mathrm{~A} 2$ & L & 10.5 & 31.5 & 3.34 & 10.9 & 31.9 & 3.36 \\
\hline 3 & $\mathrm{~A} 3$ & $\mathrm{P}$ & 7.6 & 22.6 & 3.6 & 9.1 & 27.4 & 3.7 \\
\hline 4 & A4 & L & 12.4 & 36 & 4.19 & 13 & 38 & 4.25 \\
\hline 5 & A5 & $\mathrm{P}$ & 7.8 & 21.4 & 2.57 & 9.8 & 27.4 & 3.31 \\
\hline 6 & A6 & $\mathrm{P}$ & 7.5 & 21.4 & 2.52 & 8.1 & 23.3 & 2.85 \\
\hline 7 & A7 & L & 8 & 24.4 & 2.66 & 8.6 & 25.4 & 2.88 \\
\hline 8 & A8 & L & 8.6 & 25.8 & 3.09 & 8.6 & 25.8 & 3.09 \\
\hline 9 & A9 & L & 7.9 & 23.5 & 2.74 & 10.1 & 30.2 & 3.58 \\
\hline 10 & Alo & $\mathrm{P}$ & 6.9 & 21.2 & 2.38 & 7.8 & 21.4 & 2.57 \\
\hline 11 & A11 & L & 12.2 & 37.5 & 4,15 & 13 & 37.8 & 4.2 \\
\hline 12 & $\mathrm{~A} 12$ & L & 7.3 & 20.5 & 2,44 & 9.4 & 25.2 & 2.95 \\
\hline 13 & $\mathrm{~A} 13$ & $\mathrm{P}$ & 7.9 & 23.5 & 2.74 & 10.1 & 30.2 & 3.58 \\
\hline 14 & $\mathrm{~A} 14$ & $\mathrm{P}$ & 7.6 & 22.4 & 2.61 & 8.6 & 23.8 & 3.1 \\
\hline 15 & Als & L & 8.2 & 24.8 & 2.63 & 9.6 & 29.5 & 3.4 \\
\hline 16 & A16 & L & 9.7 & 29.5 & 3.52 & 10 & 30.5 & 3.58 \\
\hline 17 & A17 & L & 9.7 & 26.7 & 2.84 & 11 & 27.5 & 2.95 \\
\hline 18 & A18 & L & 8.4 & 24.9 & 2.85 & 9.6 & 25.5 & 3.02 \\
\hline 19 & A19 & L & 8.8 & 26.5 & 3.01 & 10.2 & 28.2 & 3.01 \\
\hline 20 & $\mathrm{~A} 20$ & $\mathrm{P}$ & 7 & 20.3 & 2.41 & 9.5 & 28.1 & 3.39 \\
\hline 21 & $\mathrm{~A} 21$ & L & 8 & 21.3 & 2.8 & 8.9 & 23.2 & 2.88 \\
\hline 22 & A22 & $\mathrm{P}$ & 8 & 22.4 & 2.66 & 8.1 & 23.6 & 2.72 \\
\hline 23 & A 23 & $\mathrm{P}$ & 6.5 & 20.3 & 2.31 & 8.8 & 26.4 & 3.35 \\
\hline 24 & A24 & $\mathrm{P}$ & 9.3 & 30.8 & 3.65 & 10.3 & 35.5 & 3.75 \\
\hline 25 & $\mathrm{~A} 25$ & L & 7.8 & 23.6 & 2.54 & 9.1 & 27.5 & 2.99 \\
\hline 26 & A26 & $\mathrm{P}$ & 10.5 & 32.4 & 3.25 & 11.6 & 32.5 & 3.62 \\
\hline 27 & A 27 & L & 7.6 & 19.9 & 2.62 & 8 & 21.5 & 2.81 \\
\hline 28 & $\mathrm{~A} 28$ & L & 6.5 & 22.6 & 2.66 & 8.8 & 28.1 & 3.02 \\
\hline 29 & A29 & L & 8.2 & 23.1 & 2.96 & 10 & 24.2 & 3.1 \\
\hline 30 & A30 & $\mathrm{P}$ & 9 & 27.4 & 3.19 & 9.8 & 28.4 & 3.2 \\
\hline Minimum & & & 6.5 & 19.9 & 2.31 & 7.8 & 21.4 & 2.57 \\
\hline Maksimum & & & 12.4 & 37.5 & 4.19 & 13.0 & 38.0 & 4.25 \\
\hline Rata-Rata & & & 8.53 & $\begin{array}{l}25.3 \\
966 \\
7\end{array}$ & $\begin{array}{l}2.94 \\
4333\end{array}$ & $\begin{array}{l}9.71 \\
3333\end{array}$ & $\begin{array}{l}28.0 \\
9\end{array}$ & $\begin{array}{l}3.26 \\
0333\end{array}$ \\
\hline
\end{tabular}

Gambar 1. Distribusi kadar hemoglobin pasien GGK sebelum dan sesudah hemodialisa.

Berdasarkan gambar 1. Menunjukkan persentase kenaikan kadar hemoglobin sebanyak 29 responden(97\%), kadar hemoglobin tetap sebanyak 1 responden (3\%) dan kadar hemoglobin menurun $0 \%$. 


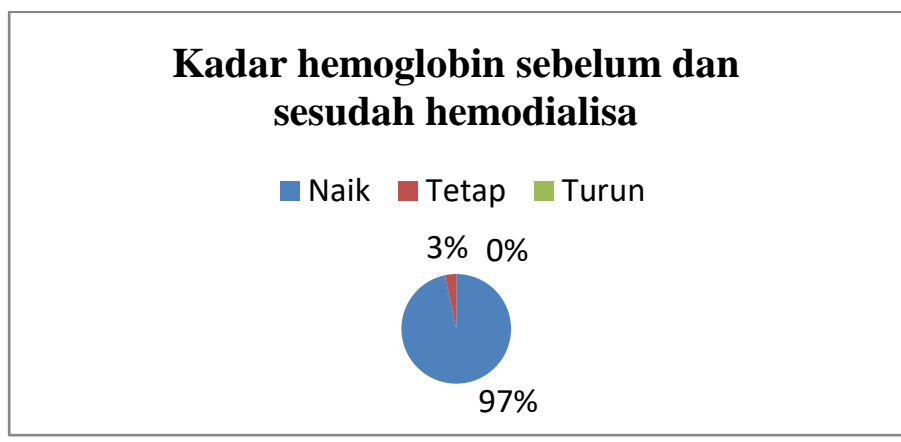

Gambar 2. Distribusi nilai hematokrit pasien GGK sebelum dan sesudah hemodialisa.

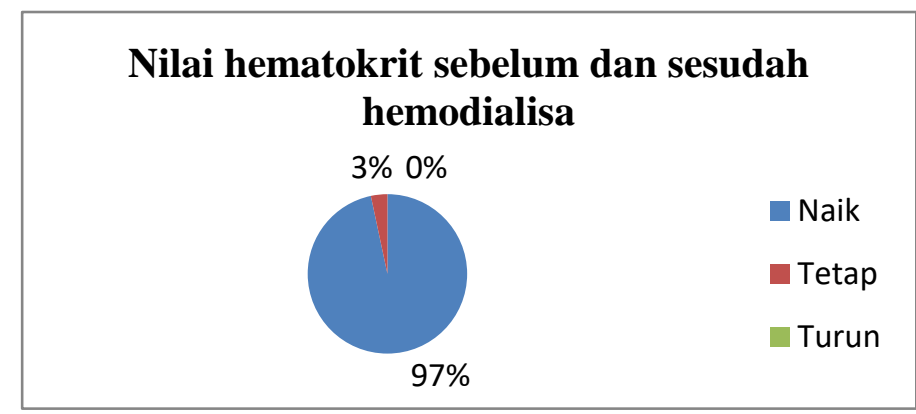

Berdasarkan gambar 2. Menunjukkan persentase kenaikan nilai hematokrit sebanyak 29 responden (97\%), nilai hematokrit tetap sebanyak 1 responden (3\%) dan nilai hematokrit menurun 0\%.

Gambar 3. Distribusi jumlah eritrosit pasien GGK sebelum dan sesudah hemodialisa.

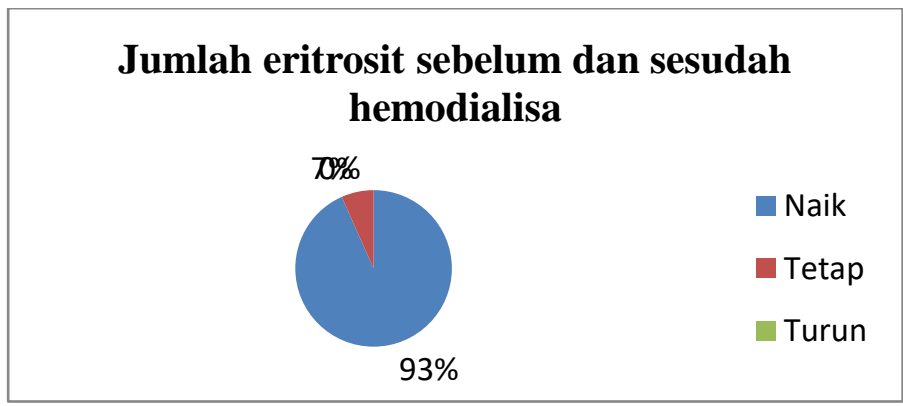

Berdasarkan gambar 3. Menunjukkan persentase kenaikan jumlah eritrosit sebanyak 28 responden (93\%), kadar hemoglobin tetap sebanyak 2 responden (7\%) dan kadar hemoglobin menurun $0 \%$.

Table 2. Tests of Normality

\begin{tabular}{l|l|c|c|c}
\hline \multicolumn{5}{c}{ Tests of Normality } \\
\hline \multirow{2}{*}{ Shapiro-Wilk } \\
\hline \multirow{2}{*}{ Hemoglobin } & Hemodialisa & Statistic & $\mathrm{df}$ & Sig \\
\cline { 2 - 5 } & Sebelum & .896 & 30 & .007 \\
\cline { 2 - 5 } & Sesudah & .928 & 30 & .044 \\
\hline \multirow{2}{*}{ Hematokrit } & Sebelum & .878 & 30 & .003 \\
\cline { 2 - 5 } & Sesudah & .945 & 30 & .124 \\
\hline \multirow{2}{*}{ Eritrosit } & Sebelum & .606 & 30 & .000 \\
\cline { 2 - 6 } & Sesudah & .471 & 30 & .000 \\
\hline
\end{tabular}


Table 2. Menunjukan bahwa data tersebut terdapat data yang terbukti tidak berdistribusi normal yaitu $<0,05$ dengan menggunakan uji normalitas Shapiro-Wilk. Dari hasil tersebut dapat dilanjutkan ke uji wilcoxon karena data tersebut terbukti tidak berditribusi normal.

\begin{tabular}{|l|c|c|c|}
\hline \multicolumn{3}{|c|}{ Test Wilcoxon Statistics" } \\
\hline & $\begin{array}{c}\text { Hb Sesudah } \\
\text { Hemodialisa - Hb } \\
\text { Sebelum } \\
\text { Hemodialisa }\end{array}$ & $\begin{array}{c}\text { Ht Sesudah } \\
\text { Hemodialisa - Ht } \\
\text { Sebelum } \\
\text { Hemodialisa }\end{array}$ & $\begin{array}{c}\text { Eri Sesudah } \\
\text { Hemodialisa - Eri } \\
\text { Sebelum } \\
\text { Hemodialisa }\end{array}$ \\
\hline $\begin{array}{l}\text { Asymp. Sig. (2- } \\
\text { tailed) }\end{array}$ & .000 & .000 & .000 \\
\hline
\end{tabular}

\section{Table 3. Test Wilcoxon Statistics}

Tabel 3.Menjelaskan bahwa tingkat signifikansi data tersebut (Asymp. Sig. 2-tailed) $<0,05$ yaitu 0,00 yang dapat diartikan memiliki tingkat perbedaan yang signifikan.

Hasil penelitian tentang perbedaan kadar Hemoglobin, nilai hematokrit dan jumlah eritrosit pada pasien gagal ginjal kronik sebelum dan sesudah melakukan hemodialisa dengan jumlah sampel 30 responden. Dapat dinyatakan ada peningkatan kadar hemoglobin, nilai hematokrit dan jumlah eritrosit sebelum dan sesudah hemodialisa dan ada yangtetap tidak ada peningkatan (perubahan) terhadap kadar hemoglobin, nilai hematokrit dan jumlah eritrosit sebelum dan sesudah hemodialisa.

Pada Pasien hemodialisa terjadi perbaikan eritropoitin yang signifikan yang menyebabkan kadar hemoglobin, nilai hematokrit dan jumlah eritrosit. Peningkatan kadar hemoglobin, nilai hematokrit dan jumlah eritrosit pada pasien setelah melakukan hemodialisa karena pasien sebelum melakukan hemodialisa mengalami hipervolemia, pada pasien gagal ginjal kronik mengalami penurunan fungsi ginjal untuk eksresi cairan dan sodium. Penurunan jumlah eritrosit, kadar hemoglobin, dan nilai hematokrit pada pasien sebelum hemodialisa karena terjadinya peningkatan jumlah cairan yang menyebabkan dilusi(Evitasari Dwitarini, Herawati, \& Subawa, 2017).Menurut (Ilmiah \& Pratiwi, 2018)bahwapada pasien PGK yang menjalani dialysis ditemukan perbaikan eritropoiesis yang signifikan. Hal ini dikarenakan pembuangan toksin uremik "suppressor eritroid" saat proses dialysis.

Data pada tabel 1. Menjelaskan bahwa kadar hemoglobin, nilai hematokrit dan jumlah eritrosit dibawah normal sebelum dan sesudah hemodialisa pada 30 respoden yang terdiri dari 18 orang laki-laki dan 12 orang perempuan.Hasil penelitian kadar hemoglobin diperoleh nilai minimum sebelum hemodialisa 6,5 $\mathrm{g} / \mathrm{dl}$ dan nilai maksimum sebelum hemodialisa 12,4 g/dl. Kadar hemoglobin sesudah hemodialisa nilai minimum7,8 g/dl dan nilai maksimum 13,0 g/dl. Rata-rata sebelum hemodialisa 8,53 dan rata-rata sesudah hemodialisa 9,713333. Hasil penelitian hematokrit diperoleh nilai minimum sebelum hemodialisa 19,9\% dan nilai maksimum sebelum hemodialisa $37,5 \%$. Hematokrit sesudah hemodialisa nilai minimum $21,4 \%$ dan nilai maksimum $38,0 \%$. Ratarata sebelum hemodialisa 25,39667 \% dan rata-rata sesudah hemodialisa 28,09\%. Hasil penelitian jumlah eritrosit diperoleh nilai minimum sebelum hemodialisa $2,31 \mathrm{juta} / \mu \mathrm{l}$ dan nilai maksimum sebelum hemodialisa $4,19 \mathrm{juta} / \mu \mathrm{l}$. Jumlah eritrosit sesudah hemodialisa nilai minimum 2,57 juta/ $\mu \mathrm{l}$ dan nilai maksimum 4.25 juta/ $\mu \mathrm{l}$. Rata-rata

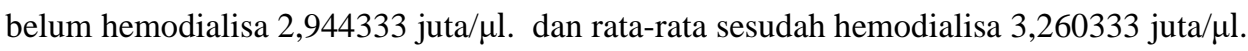


Tabel 2. Menunjukkan bahwa hasil normalitas menggunakan Shapiro-Wilk tidak berdistribusi normal disebabkan karena pada setiap parameter pemeriksaan memilikinilaisignifikan $<$ dari 0,05 . Dengan demikian dilanjutkan dengan menggunakan uji wilcoxon karena data terbukti tidak berdistribusi normal.Tabel 3. Menjelaskan bahwa tingkat signifikansi data tersebut (Asymp. Sig. 2-tailed) < 0,05 yaitu 0,00 yang dapat diartikan memiliki tingkat perbedaan yang signifikan

Pada pasien yang mengalami kenaikankadar hemoglobin, nilai hematokrit, dan jumlah eritrosit dapat dinyatakan bahwa hemodialisa efektif untuk memperpanjang harapan hidup seseorang penderita gagal ginjal kronik (Wiliyanarti, Komunitas, \& Majapahit, 2019). Pada pasien yang kadar hemoglobin, nilai hematokrit, dan jumlah eritrosit tetap dapat dinyatakan bahwa hemodialisa dapat di gunakan untuk memelihara ginjal, sampai pasien mendapatkan ginjal baru (Aru W Sudoyo, 2009).Pada Pasien gagal ginjal, hemodialisa merupakan salah satu tindakan untuk mengeluarkan sisa metabolisme dalam tubuh (Aru W Sudoyo, 2009). Tujuan utama hemodialisa adalah mengembalikan keseimbangan cairan intraseluler dan ekstraseluler yang terganggu akibat kerusakan ginjal (Ii, 2003). Hemodialisa tidak dapat menyembuhkan penyakit ginjal karena tidak mampu menggantikan fungsi ginjal sepenuhnya, pada pasien gagal ginjal kronik harus menjalani hemodialisa sepanjang hidupnya (Suzanne C. Smeltzer, 2013).

\section{Kesimpulan}

Kadar hemoglobin dan hematokrit sebelum clan sesudah hemodialisa mengalami peningkatan sebanyak 29 responden dan yang nilainya tetap sebanyak I sarnpel. Jumlah eritrosit sebelum dan sesudah hemodialisa mengalami peningkatan sebanyak 28 responden dan yang nilainya tetap sebanyak 2sampel. Secara Keseluruhan terjadi peningkatan kadar hemoglobin,nilai hematokrit,dan jumlah eritrositsebelum dan sesudah hemodialisa.

\section{Daftar Pustaka}

Adhiatma, A. T., Wahab, Z., Fajar, I., \& Widyantara, E. (2014). Analisis Faktor-Faktor yang Berhubungan dengan Kejadian Gagal Ginjal Kronik Pada Pasien Hemodialisis Di RSUD Tugurejo Semarang Analysis of Factors Related to Chronic Kidney Disease in Hemodialysis Patients of RSUD Tugurejo Semarang. Fakultas Kedokteran Universitas Muhammadiyah Semarang: volume 1-10.

Analis, A., Delima, K., \& Gresik, H. (2015). PERBANDINGAN KADAR HEMOGLOBIN SEBELUM DAN SESUDAH HEMODIALISA PADA PASIEN GAGAL GINJAL KRONIK DI RSU Dr. SAIFUL ANWAR, MALANG Rosidah *), Hanif Sumitro Utomo. Jurnal Sains, 5(10).

Aru W Sudoyo. (2009). Ajar Ilmu Penyakit Dalam (Jilid 2. E). Interna Publishing;

Evitasari Dwitarini, N., Herawati, S., \& Subawa, A. (2017). Perbedaan Kadar Hemoglobin Sebelum Dan Sesudah Hemodialisis Pada Pasien Penyakit Ginjal Kronis Di Rumah Sakit Umum Pusat Sanglah Denpasar Bali. EJurnal Medika Udayana, 6(4).

Ii, B. A. B. (2003). Hubungan Perilaku Pasien..., Akbar Dhika Tri Purwono, Fakultas Ilmu Kesehatan UMP, 2017. hal $10-20$.

Ilmiah, K. T., \& Pratiwi, L. I. A. D. W. I. (2018). PERBEDAAN KADAR HEMOGLOBIN PADA PENDERITA GAGAL GINJAL KRONIS SEBELUM DAN SESUDAH HEMODIALISA (Studi di RSUD Jombang ). 2018.

Kandarini, Y. (2017). Penatalaksanaan anemia pada penyakit ginjal kronik. volume13-14.

Khanmohamadi, S. A. (2014). In light of another's word: European ethnography in the middle ages. In Light of Another's Word: European Ethnography in the Middle Ages, 2, 1-211. https://doi.org/10.1080/13507486.2015.1047603 
Notoatmodjo, S. (n.d.). Metodologi Penelitian Kesehatan. Oliver, J. (2019). 済無No Title No Title. Hilos Tensados, 1, 1-476. https://doi.org/10.1017/CBO9781107415324.004 Diakses 10 agustus 2019 pukul 10.27

Pendidikan, P., Spesialis, D., Klinik, P., Sakit, R., \& Sadikin, H. (2016). Pemeriksaan Fungsi Ginjal. volume 43(2), hal $148-154$.

Predictors of survival among end stage renal failure patients undergoing dialysis treatment in Pahang from 2000 to 2004. (2009). Malaysian Journal of Community Health, 15(1), 75-84.

Ri, K. K. (2018). Situasi PTM di Indonesia. (November), volume 1-18.

Suzanne C. Smeltzer, B. G. B. (2013). Buku Ajar Keperawatan Medical Bedah Volume 3 - Brunner dan Suddarth.

Ulya, I. (2007). Perbedaan Kadar Hb Pra dan Post Hemodialisa pada Penderita Gagal Ginjal Kronis di RS PKU Muhammadiyah Yogyakarta The Difference of Hb Levels Pre and Post Hemodialysis in Chronic Renal Failure Patients at PKU Muhammadiyah Hospital Yogyakarta. 7(1), 29-33.

Utami, P. R., \& Fuad, K. (2018). GAMBARAN KADAR HEMOGLOBIN PADA PENDERITA DIABETES. 5.

Widyastuti, R., Butar-butar, W., \& Bebasari, E. (2014). Korelasi Lama Menjalani Hemodialisis Dengan Indeks Masa Tubuh Pasien Gagal Ginjal Kronik DI RSUD Arifin Achamad Povinsi Riau pada Bulan Mei Tahun 2014. Jom FK, 1(2), 1-12.

Wiliyanarti, P. F., Komunitas, D., \& Majapahit, S. (2019). LIFE EXPERIENCE OF CHRONIC KIDNEY DISEASES UNDERGOING HEMODIALYSIS. volume 4(1). 